\title{
Promoting 'Third Space' Identities: A Case Study of the Teaching of Business Japanese
}

\author{
Emi Otsuji, University of Technology, Sydney \\ Chihiro Kinoshita Thomson, University of New South Wales
}

In the last decade, the relations between language use, power, identity and culture have been a focus in language teaching. As such, a number of studies propose to move away from the structural and syntactic knowledge centred pedagogy and instead emphasise the incorporation of students' voice and identity positions (Giroux 1990; Giroux et al. 1996; Giroux \& McLaren 1994; McLaren 1994; Pennycook 2001; Norton 2000; Norton $\&$ Toohey 2004). These studies suggest the importance of constructing new hybrid identities in a foreign language, and indicate that one of the aims in teaching is to support students in constructing their own identities. Within this context, what does it mean to promote student identity construction in a foreign/second language? In particular, what does it mean to incorporate cultural and linguistic backgrounds and identities of students in language teaching and learning? How are the content of the textbook, the teacher's ideological position, the structure/objectives of the course, and classroom practices related in terms of students' identity construction? This study attempts to respond to these questions by building on previous studies that emphasised the importance of representing diversity in the language classroom.

In this study, in order to explicate students' linguistic and cultural identity construction, we chose the treatment of gender in business Japanese language teaching and learning practices as a case study. Japanese is a language that shows marked linguistic distinction between so-called masculine and feminine styles, although there is, in fact, a large area

PORTAL Journal of Multidisciplinary International Studies, vol. 6, no. 1, January 2009.

'The Space Between: Languages, Translations and Cultures': Special Issue edited by Vera Mackie, Ikuko Nakane, and Emi Otsuji. 
of overlap in most areas of language usage by men and women (Masuoka \& Takubo 1992). Moreover, the Japanese business industry is considered by some to be masculine in its style of interaction. Japanese language teaching practices, for example in textbook content and classroom activities, often assume that business personnel are male (Armour 1998; Kawasaki 1997; Thomson \& Otsuji 2003). To this end, the study explores the ways in which gender representations in textbooks, the treatment of gender, and a teacher's ideological stance towards gender, work together to constitute students' identity construction in the classroom. By unpacking the interconnectedness of these practices, we extend the argument from specific gender identity to more general identity issues. We suggest that limitations placed on teaching and learning practices to promote student identities as active transcultural learners can be addressed by awareness of the 'third space'; that is, by rethinking the classroom as a third space where two or more cultures meet, different cultural practices can be acknowledged, adapted and appropriated. This has implications not exclusively at the micro-level of textbook content and the teacher's treatment of the textbook in classroom activities, but also at macro institutional, cultural and political levels.

\section{Background of the study}

A number of studies claim the importance of incorporating the diversity of Japanese language use and culture into the Japanese language classroom. One study dealing with diversity within Japanese culture is by Matsumoto and Okamoto (2003), which compares textbook dialogues with actual spoken data and proposes the importance of introducing the varieties of Japanese language evident in sociolinguistic data. Even though their study acknowledges the problem of the mere representation of stereotypical language use in textbooks, it is limited in that they do not seem to go beyond a prescriptive approach. That is, there is a danger of imposing on language learning a particular register, and of essentialising sub-groups by gender, social status, class and other categories. Another approach to diversity can be seen in the works of other scholars (Kawasaki 1997; Ohara et al. 2001; Siegal \& Okamoto 2003; Kubota 2003) for whom critical discussion of Japanese language and culture is essential for raising awareness of diverse practices. For example, Kubota (2003: 76) encourages teachers to become critical consumers of the given textbook by using descriptive rather than prescriptive practices, by acknowledging both the dynamism and diversity of culture, and by understanding the multiple meanings of culture as a historical and political 
construct. Kawasaki's study on gendered language (1997: 67) proposes that the role of teachers is to provide different voices within Japanese society and to support learners to find their own language.

One aspect of diversity that has been inadequately addressed is the impact of the "nonnativeness' of the learner. Although Kubota claims to avoid either essentialisation or overdetermining Japanese culture and language, she does not really look at students' individual positions from the point of view of 'non-native' speakers of Japanese. ${ }^{1}$ Siegal and Okamoto (2003: 58) point out that different expectations and ideologies are imposed on 'non-Japanese' speakers and 'non-native' speakers in Japanese-speaking society. They suggest that the ideological difference attached to 'non-native' speakers needs to be considered in the teaching of Japanese. Nevertheless, Siegal and Okamoto do not elaborate on these suggestions. Along the same lines, Kawakami (1999: 24) addresses the 'positionality' of students in the teaching of Japanese culture; that is, how Japanese culture can be interpreted differently by students with different ideologies, backgrounds and positions. However, the study is based on the teaching of culture rather than language. Armour (1998: 197), in contrast, explicitly proposes that language textbooks should contain dialogues between 'native' and 'non-native' speakers since different norms would apply to both groups. The different positions and expectations imposed on students as 'non-native' speakers in a Japanese-speaking community have thus prompted us to think about the ambivalent space occupied by 'non-native' speakers of Japanese and learners of Japanese language. However, this focus also exposes the danger of essentialising 'non-native' speakers' positions in opposition to that of 'native' speakers. This comparison should be carefully treated when dealing with the position of 'non-native' speakers.

Of importance, then, is the impact of the teacher and of the textbook in what is effectively the construction of student identity as 'non-native' speakers or 'Japanese' within the ambivalent space of foreign-language learning. Siegal and Okamoto's (2003) study examines textbooks in relation to the representation of norms and diverse gender practices. They propose to incorporate students' voices in teaching and make suggestions about the type of materials and activities that would enhance students'

\footnotetext{
${ }^{1}$ Inverted commas are used around the word 'native' and 'non-native' to acknowledge the complex issues and critical disagreements over what constitutes native and non-native speakers.
} 
awareness of the tension between diversity and dominant norms. However, they do not explore one important implication of this tension, the dynamic process that such contact entails, and which has been called transculturation (Pratt 1992; 1994) and the 'third space' (Bhabha 1990; 1994; 1996). In other words, their study is more disposed to a dichotomous approach (norms versus other non-dominant practices within Japan) rather than allowing for the productive and ambivalent space and contacts in between norms and other non-dominant practices in which students construct their own identity position as Japanese language learners. Correspondingly, even though Siegal and Okamoto's (2003) study includes the content of a textbook, and the views of students and teachers, it does not examine the inter-relationships between texts, students and teachers. Analyses by Sunderland et al. $(2001 ; 2002)$ on the use of English as a Foreign Language (EFL) textbooks by teachers demonstrates that the ideological position on gender held by teachers can override the purported gender-free ideology of the textbook. This indicates that the intention of the textbook may not always be translated into classroom practice, and suggests the importance of research into the ways in which different ideologies and intentions are intertwined in teaching and learning practices and how those convergences have an impact on students' identity construction.

\section{Unpacking multi-layered teaching and learning practices}

In order to answer the research questions posed at the beginning of this essay, we undertook a case study approach. We had access to one business Japanese subject taught at an Australian university. We analysed the textbook used, collected interview data from one teacher and two students (see Appendix one and two), and observed two class periods, one in mid-term and another towards the end of the term. ${ }^{2}$ In the observed lessons, the teacher used the textbook and the two students were present. The subject, and how it was situated within the larger Japanese program at the university, were also examined. Classroom observation and interviews were audio-recorded and transcribed. Although this study is a case study based on a small sample, its ethnographical approach and use of multi-layered and in-depth data analysis do provide useful insights into the identity and cultural issues that influence the teaching of language.

\footnotetext{
${ }^{2}$ In the teacher and student interviews, questions were posed in stages so that the interviewees could express their views more freely without being influenced by the objective of the research. In the first stage, general questions were asked. Specific questions on gender were asked in the second stage.
} 


\section{The subject}

The subject in our case study is an upper elementary to lower intermediate level Japanese language subject, entitled 'Professional Japanese,' taught at a large university in a major city in Australia. This was one of the elective Japanese subjects offered to students majoring in Japanese Studies, although non-major students also took the subject. The subject was taught for three hours per week over a 14 week semester. All 37 students were of Asian ethnic backgrounds, including those who were born in Australia. Their countries of origin were Australia, Hong Kong, Taiwan, Korea and Indonesia, with the predominant group being Chinese ( 72 percent of students). There were only five male students. There were two main components in the subject: minipresentations by the students, and the lessons taught by using the textbook. In most of the classes, the first half of the lesson was spent on the presentation, and the latter half of the lesson was spent on teaching from the textbook. The two classes that we observed and audio-recorded were the latter half of the lessons.

\section{The textbook}

The course used the textbook, Getting Down to Business: Japanese for Business People (Yoneda et al. 1998). The target readers of the textbook are business people learning Japanese at lower intermediate level. The textbook has eight function-based lessons. Functions include giving and receiving permission, and making requests. Model conversations and role-plays are set in both intra-company and inter-company situations. The characters in the textbook appear as non-gender specific and nonnationality specific; indeed, the conversations in the textbook did not in general carry designated names or gender, as shown in Table 1. However, native speaker dominance, signified by the lack of non-native speaker managers and by non-native female invisibility is found throughout this textbook (Table 1).

Unlike the Japanese language textbooks discussed in earlier studies (Thomson \& Iida 2007), this textbook does have a named non-native speaking female, a female section chief, another female boss, and other deviations from a stereotypical male-female Japanese business relationship in which a male is usually given a higher role than a female worker, one often characterised by gendered language. Other notable features of the textbook are that males and females sometimes speak in the neutral forms of two equals (Example 1 below), female superiors occasionally speak in to male subordinates 


\begin{tabular}{|c|c|c|c|c|c|}
\hline & \multicolumn{2}{|l|}{ Female } & \multicolumn{2}{|l|}{ Male } & \multirow{3}{*}{$\begin{array}{l}\text { Total } \\
\text { No }\end{array}$} \\
\hline & NJF & JF & NJM & JM & \\
\hline & No (\%) & No (\%) & No (\%) & No (\%) & \\
\hline Overall & \multicolumn{2}{|c|}{$58(39.46 \%)$} & \multicolumn{2}{|c|}{$89(60.54 \%)$} & 147 \\
\hline \multirow[t]{2}{*}{ Named Characters } & $1(3.85 \%)$ & $4(15.38 \%)$ & $6(23.08 \%)$ & $15(57.69 \%)$ & \multirow[b]{2}{*}{26} \\
\hline & \multicolumn{2}{|c|}{$5(19.23 \%)$} & \multicolumn{2}{|c|}{$21(80.77 \%)$} & \\
\hline \multirow[t]{2}{*}{ Managers } & $0(0 \%)$ & $2(25.00 \%)$ & $0(0 \%)$ & $6(75.00 \%)$ & \multirow[b]{2}{*}{8} \\
\hline & \multicolumn{2}{|c|}{$2(25.00 \%)$} & \multicolumn{2}{|c|}{$6(75.00 \%)$} & \\
\hline
\end{tabular}

Table 1: Number of Characters by Gender and Language Background.

$\mathrm{NJF}=$ Non-Japanese Females; JF = Japanese Females; NJM = Non-Japanese Males; $\mathrm{JM}=$ Japanese Males; Gender was determined by listening to the accompanying audio tape.

in a manner suitable for a person in power, male subordinates offer to help female superiors (Example 2 below), and females at times express opinions.

Example 1: Lesson 5, Role-play conversation 2 (p.75). On the tape, A is female and B is male.

A: Suzuki-kun, konban yotei aru? [Suzuki, any plans tonight?]

B: Iya, betsu ni nai kedo... [Not really.]

A: Hisashiburi ni isshoni nomi ni ikanai? [Why don't we go out for a drink for a change?]

B: Iyā, sore ga saikin zangyō ga tsuzuite iru $n$ de, kyō wa hayaku kaerō to omotte iru $n$ da.

[Well, I have been doing a lot of overtime these days, and I was thinking about going home early today.]

A: Mā ii ja nai, kyō dake wa. Shinjuku ni ii tokoro o mitsuketa n da.

[Won't you make an exception today. I found a good place in Shinjuku.]

B: Un, dakedo, kono tokoro tsukarete ru shi, yappari yame toku yo. Mata kondo ni shite kureru?

[Yeah, yeah, but I am sort of tired, and I shouldn't. Could we take a rain check?]

A: $S \bar{o}, j a$, mata kondo. [OK, some other time.]

The female speaker A does not use any typical 'feminine language' in this role play conversation, and her part could easily be taken by a male speaker. Her speech is more in line with the 'masculine language,' and thus some deviations from 'male/female language' norms can be observed in this textbook. ${ }^{3}$

\footnotetext{
${ }^{3}$ From the perspective of Japanese female/male language 'norms' (Ide 1982; Ide \& Yoshida 1999; Makino \& Tsutsui 1989: Yoshioka 1994), the following deviations can be observed.

- Female speaker A initiated the conversation and invited male speaker B out for dinner/drinks. This deviates from the 'norm' that men invite women.

- Female speaker A's invitation is in rather direct, informal and 'male-like' language. This use deviates from the 'norm' that women prefer to make indirect invitations when conversing with someone with equal status or higher.

- Both male and female speakers applied the sentence ending 'noda/nda.' This form is normally seen as masculine expression and deviates from female language norms.
} 
Example 2: Lesson 8, Stage 2, Intra-company situation (p. 127). On the tape, A, a superior, is female; $\mathrm{B}$, a subordinate, is male.

A: Jōnzu-san, raishū kinyōbi ni Sanfuransisuko shisha no Sasaki shishachō ga Nihon ni irassharu koto ni natta no.

[Mr. Jones, it's been decided that Mr. Sasaki, the manager of our San Francisco branch is coming to Japan on Friday next week.]

B: $\bar{A}$, Sasaki shishachō desu ka. Watashi mo Amerika ni ita toki ni wa iroiro o-sewa ni narimashita. Natsukashii desu ne. Mō are kara, go-nen ni narimasu.

[Ah, Mr. Sasaki, I was under his care during my stay in the US. It brings me back fond memories. It's already been 5 years since then.]

A: Sore de, kinyōbi ni uchi no ka de nomi-kai de mo yarō ka to omotte iru $n$ da kedo ...

[Well then, I am thinking about our section hosting a party for him on Friday, and ...]

B: $\bar{E}$, ii desu ne. yoroshikattara, kanji o shimashou ka?

[It sounds good. If you'd like, shall I organise the party?]

A: $\bar{A}$, arigatō. Tasukaru wa. Ato Narita e no demukae na $n$ da kedo...

[Oh, thank you. That'll be good. And, then, about the reception at Narita ...]

B: Dewa sore mo watashi ga yarimashō. [Well, I will do that too]

A: Iyā, Jōnzu-san wa kanji de taihen da kara, Kimura-san ni tanomu wa. Arigatō.

[No, since you are busy with the party organization, I will ask Mr. Kimura. Thank you.]

Furthermore, both speakers can be considered as having equal status and belonging to the same age group. This is evident in the use of 'Suzuki-kun' by the female speaker A when addressing the male speaker B. 'Kun' is the address term generally used for male speakers who have equal or lower status (Makino \& Tsutsui 1989: 211). Recent studies show that male and female co-workers of the same age group use the same type of language (Kawaguchi 1987), female speakers manipulate their language use according to the situation (small talk, meeting etc.) and use 'masculine language' accordingly (Takahashi 2002), and the sentence ending gendered distinction has become less prominent than in the past (Endo 2002a; 2002b). This role-play, then, seems to reflect recent language changes and conventions in Japanese society.

What sets this example apart is the reversed role from the conventional roles between males and females, as well as between Western and Japanese people. Speaker A is a Japanese female occupying a superior speaking position, and speaker B is a non-native Western male. Furthermore, Speaker A uses a 'masculine expression, 'iyā,' [no] and this again echoes the dynamic change in language use by males and females.

The above excerpts show that the textbook incorporates female superiors and male nonnative speakers, and thus provides representations other than stereotypical male-female business relationship and language uses. The inclusion of non-native male and female speakers indicates that some acknowledgment was made of first, the existence of nonnative speakers in the business world, and second, the dynamic change in female/male 
language uses in the contemporary workplace environment (Example 1). Nevertheless, given that non-native speakers of either gender appear significantly less often than native speakers, and that they were not given managerial positions, the textbook demonstrates a native-speaker bias (Table 1). Furthermore, most of the exercises in the textbook are grammatical drills and set role-plays, and the textbook fails to provide any opportunity to critically discuss the social implications of the drills and role-plays for native speakers and non-native speakers alike, and for gender relations. Thus it is left to the users (teachers and students) as to how these issues are understood, consumed or ignored. In other words, the textbook provides some insight into new ways of representing Japanese business language use, but it does not go further than the provision of a few examples.

\section{The teacher: 'I taught [what was in] the textbook'}

The teacher, a native Japanese female in her mid-forties, has more than twenty years of experience teaching Japanese at university level, including in a business Japanese subject. She has a high level of awareness of the diversity of Japanese society; indeed, at the time of data collection, she was pursuing a post-graduate degree in the field of Japanese Studies. The teacher was interviewed at the conclusion of the subject by one of the researchers in an attempt to find the rationale behind her use of the textbook in relation to gender in the classroom. Issues discussed included the teacher's general assessment of the textbook, the objectives of the classes, the textbook's treatment of gender, and the teacher's views on gender in the business community.

In the interview, the teacher stated that although this book was used as the main textbook for the course, it was not quite suitable for her students. She was aware that the textbook lacked adequate sociocultural explanation and showed a preference for situations involving only 'native' Japanese speakers. According to her, the majority of her students wished to work for non-Japanese trading companies that have business relations with Japanese companies, and did not consider working for a Japanese company to be their first employment preference. The teacher noted that female learners would not be placed in the same positions as Japanese female workers if they were to work in Japanese companies, and they would be unlikely to be hired to do clerical and administrative work, as in the case of female native speakers. The teacher's underlying assumption, therefore, was that non-native female speakers would more likely be hired 
for their professional skills in combination with their Japanese language proficiency. As a result, the teacher felt that a non-native speaking female could not simply be put into the same category as a native Japanese-speaking female who is stereotypically seen as someone doing an administrative job. This perception is supported by Nakada's (1998: 16) suggestion that non-Japanese women in business constitute a third gender in the world of Japanese business. Writing of such women, she notes that 'their Japanese male business contacts do not expect them to think or act or live within the same ironclad cultural boundaries as Japanese women' (Nakada 1998: 18). The teacher pointed out that this tendency in the textbook to impose 'native' varieties of language use on students did not provide room for learners to think critically about their gendered positions in Japanese business culture.

With regard to the treatment of gender, the teacher stated that her basic stance was that it is entirely up to the individual to choose which type of language to use in a particular context:

Students can decide whether or not to use male or female language. However, it is better for them to know, for their information, what sort of reaction they will receive to, for example, the use of female language by a male. With that knowledge, based on their own attitude, if they still want to use particular language, I think that is fine. ${ }^{4}$

On the other hand, notwithstanding her awareness of the complexity of students' positions as non-native speakers entering the Japanese business world, she was not able to emphasise this in her class due to the tight curriculum: 'I did not have time in the end to practise conversation from the students' perspectives. This time, I only taught [what was in] the textbook.' She added: 'This time, I followed the textbook content. I taught the course not by using the textbook but I taught the textbook. I did not make any special concessions to their [the students'] positions.' Thus, there was a discrepancy between what she believed and what she did in her actual teaching practices.

\section{The classroom}

In our observation of her teaching, the teacher appeared to stay neutral in terms of gender. She focused on the textbook content, especially the grammar structures and vocabulary, and did not seem to have time to explore other areas, such as the personal relationships between the characters in the dialogue, or their gender representation. Both classes were conducted mostly in a teacher-led style. The teacher followed the textbook

\footnotetext{
${ }^{4}$ English translation of the teacher's answer. The original interview was conducted in Japanese.
} 
content. She read the dialogue with the class, explained its meaning and grammar in English, played the tape for students, had the students practise the dialogue in pairs, and had some of the pairs present their dialogues to the class. In other words, her classroom practices confirmed her remark that she faithfully followed the content of the textbook, with little room left for her to reflect on her teacher's ideology and teaching philosophy. This might partially be due to time constraints, as the teacher pointed out. It is also possible that the class size and the demography of the students (gender and ethnic background) also affected her classroom activities. The class of 37 students is large for language tutorial style teaching, and this factor may have also affected the style of teaching and the class activities that we observed.

\section{Students: 'Not as a Japanese woman nor as a foreigner'}

We interviewed two students from the class. Two Chinese female students, Kate and Amanda (pseudonyms), were chosen because while the students in the class were of Asian backgrounds, Chinese students made up the dominant group (72 percent), and the overwhelming majority were female (32 out of 37). The rationale behind the choice of the two female students was to look at how female students perceive and respond to the treatment of gender issues in the textbook and in class. Both students ranked in the top ten percent of students in the subject and attended classes regularly. We thus considered these two students to have sufficient information and experiences to answer interview questions regarding the textbook and classroom activities.

Kate, aged twenty-one, was from Hong Kong. She had lived in Australia between the ages of four and six, and returned to Australia at the age of fourteen with her family. Her first language was Cantonese. She also spoke Mandarin and English. Amanda, aged twenty-one, migrated from Taiwan to Australia with her family when she was ten. However, her parents returned to Taiwan and she remained in Australia with her sister. Her first language was Taiwanese and she also spoke Mandarin and English quite well. In addition to Japanese she was learning Cantonese at the time of the interview.

Both Kate and Amanda noted that the textbook showed a difference in language use between females and males. They did not seem to notice that the textbook contained non-stereotypical gender roles in terms of the Japanese business arena. In addition, they pointed out that the textbook lacked cultural and business background information and 
that neither the content of the subject, nor the textbook, encouraged them to think critically about their positions. Their beliefs corresponded with that of the teacher when she noted that she did not address cultural identities and positions in her class.

With regard to the treatment of gender, Kate and Amanda were ambivalent for different reasons. Amanda did not find the adoption of 'female language' problematic, but she did find it frustrating because she was not able to practise using it appropriately. Kate showed reservations about adopting the gendered language. The following statements show her dilemma and struggle.

It gives me a clash of identities because one way, my Asian Chinese background say [sic] men and women should be equal and on the other side, Japanese women are, in order to be more Japanese, you should accept the way how things work between Japanese male and female.

Yes, I want to be more acceptable. Not as a Japanese woman nor as a foreigner. A combination. I think the middle of a Japanese and foreigner. If they treat me like very foreign, it is very hard to communicate with them. As a Japanese woman, I might not have the same level to talk with them either. So I rather want to be in the middle. Not too foreign but not too Japanese woman. (emphasis ours)

Nakada's (1998) proposal that non-Japanese women in business do not have a designated position in business society had not been made explicit to Kate, either in the textbook nor in the classroom. In other words, she did not seem to have received any assistance in going beyond the position normally expected of a woman in the Japanese business community, let alone in constructing her own identity as a non-native female speaker.

Amanda, on the other hand, had a different position. Rather than establishing a position as someone located between her own and the target culture, she seemed to have had an assimilative approach to learning. As she stated: 'I am trying to become like a Japanese. I can forget about my Chinese background when speaking in Japanese. I want to be treated like a Japanese.' This statement, on the surface, sounds as if Amanda did not experience the identity crisis that Kate did in adapting to conventional Japanese gendered practice. However, Amanada revealed that she was indeed searching for her own position amid various competing cultural and linguistic practices: 'I don't really like to be in a top position. My personality is more like working for other people. I think it is my personality that I don't want to be in a decisive [sic] making position. I would rather listen to other people. I am not a typical Chinese.' 
Amanda claimed that she was not a typical Chinese business woman; she felt uncomfortable within her own Chinese environment. She noted that her personality and career goals were more in keeping with the stereotype of Japanese female business culture. It is thus possible that Amanda experiences some identity friction when dealing with her gender identity in a Chinese business context, and is in search of a comfort zone for her identity construction. Amanda shared one anecdote about her learning experience that exemplify the gendered limits to her goal to 'become like a Japanese': she prepared a role-play conversation by using a model conversation from the textbook and showed it to a Japanese friend, only to have it pointed out that she sounded like a male speaker. She was frustrated that the textbook and the classroom activity did not allow her to learn to speak like a Japanese female.

It seems apparent from these two examples that there are differences in their prospective positioning in terms of gender identities within the target learning community. However, neither the textbook nor the classroom activities supported students in gaining deeper understandings of gender complexities as they influence Japanese language teaching and learning.

\section{Promoting a 'third space'}

In this study, the textbook contained some non-stereotypical representations of gender mores and included non-native female speakers. The teacher of the subject was aware of the ambivalent position in which non-native female speakers would be placed in a Japanese business setting. Both students in this study also demonstrated that they did indeed think independently and differently about their own gender identities and prospective positioning. Even so, no critical activities were initiated to support students in constructing and performing their own identities in the class. As a result, both Kate and Amanda were left to find their own ways of performing their identities in the target linguistic community. A number of questions thus arise. How can Kate establish her position as 'neither Japanese nor foreign female,' and how can the language class support developing this identity position? Correspondingly, how can Amanda develop an ability to speak and perform her version of a 'Japanese female'? Do classroom activities, such as making up dialogues based on the textbook content, sufficiently support Amanda to construct her own position and desire to behave as a 'Japanese female'? More generally, how can the above two contrasting positions be supported in 
the same class using the textbook taught by the same teacher? In light of the critical literature and debates noted earlier, these questions indicate a need to move away both from the imposition of monolithic native-speaker norms and the mere provision of diversity practices in the language learning setting. Instead, explicit opportunities for students to consider the degree to which they adapt target cultural and linguistic practices to establish and perform their own subject positions and identities are required.

The data used in this study indicates that there were discrepancies, gaps and overlaps between the textbook content, the teacher's ideology, classroom activities, university teaching structures, and students' gender identities. Although the textbook included deviations from normative Japanese gender practices, those deviations were not elaborated upon by the teacher and the students. There was also a gap between the teacher's ideological stance and the actual classroom activities she conducted. The teacher's ideological stance (for example, her acknowledgement of the ambivalent subject position of her students) was undermined by the demands placed on her by university teaching structures (size of the class and the contact hours). What, then, are the pedagogical implications of this study? By mobilising the notion of the 'third space' (Bhabha 1990; 1994), the next two sections explain our case study from a theoretical perspective in order to suggest a pedagogy that would minimise the aforementioned gaps and promote students' identity construction in the language-learning process.

\section{The 'third space' and students' identity construction}

The notion of the 'third space' is proposed by Bhabha in his contributions to postcolonial theory $(1990 ; 1994 ; 1996)$. He questions the conceptual usefulness of the term 'diversity, and instead proposes the 'third space' to designate the emergence of a hybridised culture where two different cultures meet: 'Hybridity to me is the "third space" which enables other positions to emerge. This third space displaces the histories that constitute it, and sets up new structures of authority, new political initiatives, which are inadequately understood through received wisdom' (Bhabha 1990: 211). Bhabha conceives the third space as an ambivalent, yet productive space in which new discursive positions emerge. In the third space, Bhabha notes, people take on a hybrid identity with emancipative and transformative power.

Bhabha's vigorous articulation of cultural hybridisation as a mode of emancipative and strategic power has been widely influential, and the notion of the 'third space' has been 
applied to various disciplines, including applied linguistics (Lo Bianco et al. 1999; Kramsch 1993, 1995). In that field there is now a shift to viewing language teaching as involving more than structural and syntactical knowledge (Kramsch 1995). The symbiotic relations between language use, power, identity and culture are seen as playing a central role in teaching and learning language (Giroux 1990; Giroux \& McLaren 1994; McLaren 1994; Giroux et al. 1996; Norton 2000; Pennycook 2001; Norton \& Toohey 2004). These studies suggest that the process of constructing identity in a foreign language learning context involves acknowledging, adapting and appropriating different cultural and linguistic practices; that is, language learning entails the production of a new, hybrid identity. ${ }^{5}$

When one of the aims in teaching is to support students to construct their own new hybrid identities, the concept of the 'third space' and its adoption in teaching language is highly productive, as some critics have argued. For example, Lo Bianco et al. (1999) propose that finding the intermediary place between the target culture and the native culture of learners, that is, neither maintaining one's own nor accommodating the target cultural orientation, is vital. Kramsch (1993: 247) argues that the learning of a foreign language is to step into a 'third place,' that is, the intersection or convergence of multiple native and target cultures. ${ }^{6}$ These studies move beyond the prescriptive approach by allowing students to find their own position in a third place/space rather than focusing on pre-existing practices. ${ }^{7}$ Kramsch (1993: 234) claims that students need to acknowledge differences within themselves and see themselves within the historic context of their own biography in order to create personal meanings and define their positions in relation to native and target cultural practices.

\footnotetext{
${ }^{5}$ Although the epistemological and ontological implications of the 'third space' were not addressed by Lo bianco et al (1999) and Kramsch (1993) when they adapted 'third space' in their works, it is useful to acknowledge that the notion has both limits and possibilities. In cultural studies and social science scholarship, and other disciplines, there has been a debate over Bhabha's theoretical approach to hybridity in relation to the 'third space.' Of note are the critical disputes with the celebration of 'hybridity' as an unproblematic category of cultural diversity that somehow provides solutions to sociocultural relations and conflicts (see, for example, Perera 1994, and Allatson 2001). The uncertain epistemological ground on which hybridity is constituted is noted by Easthope (1998) and Kraidy (1999), who argue that it is hard to define where hybridity starts when all everyday cultural practices are inherently more or less hybrid, notwithstanding Bhabha's claim that hybridity can be defined against what is not.

${ }^{6}$ Kramsch (2005) uses the term 'third place' rather than 'third space,' even though her discussion is indebted to Bhabha's notion of 'third space.'

${ }^{7}$ Here, the term 'third' refers to the position that students construct in the process of negation between $1^{\text {st }}$ (one's original language) and $2^{\text {nd }}$ (the target language) practices.
} 
The interviews with students we conducted for this study indicated that individual biographies, cultural backgrounds and personalities had an impact on students' capacities to conceive their language learning in terms of a 'third space' process of identity construction. Kate stated that she wanted to be neither Japanese nor a foreigner, but someone in between. Amanda, in her way, was searching for her own 'third space' as a reaction against her identity crises in a Chinese business community; she took a conformist position in relation to dominant Japanese language and cultural practices. In other words, Kate and Amanda were implicitly engaged in constructing their identities in-between distinct linguistic and cultural spaces. However, neither the textbook nor the teacher were able to provide them with opportunities for performing their gender identities in their own 'third space' in relation to their individual biographies, subjectivities and desires, or to their capacities to recognise power relations. The need to facilitate such performances has been noted by Pennycook (2001), who proposes that language teaching and learning need to account for the social changes they produce by heeding such factors as power relations, subjectivity differences and desires. The data in this study, as well as recent trends in language teaching, suggest that pedagogy needs to move beyond astatic and discrete understanding of language and culture in order to 'set up new structures of authority, new political initiatives' (Bhabha 1990: 211).

\section{'Third space' pedagogy and its application to teaching practices}

Healy (2008) and Dooley (2008) state that learning occurs when individual differences and voices_-learners' individual subjectivities — are incorporated in teaching and learning practices. Building on this idea, Healey (2008: 10) proposes that a new pedagogy needs to acknowledge the role of individual agency in learning. Following this tenet, and in accordance with our previous discussion of a 'third space,' we argue for the importance of pedagogy that provides an opportunity for students to renegotiate their own identities. Developing explicit awareness on the part of students that they are placed in an emancipative 'third space,' would promote student learning and further enable students to construct identities as agents in the target linguistic community.

We have already noted that the intention of the textbook and the teacher's ideology were not necessarily translated into classroom activities in order to meet students' needs. This suggests that consideration of the coherent link between textbook content, teachers' understanding, and the teaching content in terms of a 'third space' is required 
to promote student identity constructions. Preferably there should be explicit incorporation of the 'third space' into the content of textbooks. It is also essential that teachers have a clear understanding of the 'third space' and an ability to integrate this understanding into classroom activities. In this regard, teacher awareness becomes a nexus between the textbook and classroom learning experiences.

It may not be reasonable, however, to expect that every language teacher has the time or opportunity to critically consume the given textbook. Nor should we assume that teachers are able to teach content that is not stipulated in the textbook. The macro level of institutional and social structures may prevent teachers from fully engaging in critical pedagogical practices, especially if the textbook does not explicate its underlying philosophy or theory of pedagogy. Maruyama (2008) notes that the language textbook per se embodies the language and teaching ideologies of textbook writers, and this in turn largely determines the teaching content. Taking account of those constraints, the language textbook should then include instructions, examples, exercises and activities that provoke students to critically engage in constructing their own identities and subjectivity positions in relation to the target community. Furthermore, the teachers' manual should also elaborate on the philosophy underpinning the textbook.

Textbook content, then, needs to provide variety. The dialogue should be appropriated from authentic material. It should contain both 'native-native' scenarios, 'non-nativenative' scenarios, and 'non-native-non-native' scenarios, in a variety of relationships and contexts. Interviewing 'non-native' speakers about their experiences could provide useful resources for textbooks. Some critical activities and questions regarding the dialogue should be included in the textbook in order to examine, as Kubota (2003: 81) suggests, how dialogue is a historical and political product. Questions about the biographies of dialogue participants should be included. Finally, after critical discussion of the impact and effect of different language choices, role-play activities can give students an opportunity to investigate how and why they perform as they do in a given cultural and linguistic context. This type of content would enable not only students, but also teachers, to develop the agency required to negotiate their identity positions in language learning and teaching settings.

\section{Conclusion}

The aim of this case study was to explore the ways in which the content of the textbook, 
the subject, classroom activities, and the teacher's ideology, are interconnected in the construction of student identities. In particular, we scrutinised he treatment of gender issues in the teaching of a Japanese business language subject. The close examination revealed the disjunction between the content of the textbook, the teacher's ideology and classroom activities due to a number of possible factors, including economic and institutional constraints. As a result, even though the students were implicitly attempting to construct their own 'third space,' they were unable to engage in constructing their own prospective subjective positions in relation to the Japanese speaking business community.

In response to the treatment of gender identities in a specific language teaching and learning context, we propose incorporating the concept of the 'third space' in teaching and learning practices. Although our conclusions are drawn from limited data in a case study, that data nonetheless points to the importance of integrating the concept of "third space' in language learning. Allowing students to acknowledge and explore the ambivalent position they occupy in a language learning setting can provide a pedagogy that goes beyond dichotomous understandings of language and culture. This strategy may enable students to find their own individual subject position by drawing on their own biographical and cultural resources. Furthermore, this mode of teaching endorses the emancipative and agentive power that students have, and provides them with a means of thinking about how their own identity positions are constructed. We also suggest that the incorporation of the 'third space' would be most effective in supporting student identity constructions when textbook content, the teachers' ideological position, and the classroom activities converge and are rendered transparent. That said, our study also highlighted the challenge of how to manage the limitations imposed by wider power and institutional structures. Notwithstanding those constraints, we propose that the explicit demonstration of the 'third space' in textbook content and in the teacher manuals may facilitate language-learner identity construction. Students and teachers would benefit from reflecting and acting upon their roles as active agents in the emancipatory third space. The specific issue of teacher identity construction in this third space needs to be explored and further elaborated in future research. 


\section{Appendix 1}

Teacher's interview questions

About the textbook

- Why did you choose this textbook?

- What was the role of the textbook in the class? Was it used as a main text or as a supplementary text?

- What is your general impression of using this textbook?

- What is the strength of this textbook? What did you like about this textbook?

- What do you think was the weakness of this textbook? What sort of difficulties, if any, did you have when using the textbook?

- If you were to revise the textbook, how would you change it?

- Who do you think the target learner for this textbook was? What sort of learners would you recommend this textbook to?

About the class and the use of the textbook in the class

- How did you use this textbook? Was there anything in particular that you took into consideration when using this textbook?

- What did you want your students to learn in the class? What were the objectives of your class?

- What sort of target students did you have in mind when you used the textbook?

- Do you normally take the diverse background of the students into consideration when you teach? If so, how?

- How do you treat the diversity of students in your classroom in terms of racial, generational and gender differences?

- What do you think about the gender treatment in this textbook?

- How did you treat gender issues in your class?

- Do you think it is better to highlight gender issues when teaching?

- When teaching business Japanese, in your opinion, how do gender issues need to be treated? 


\section{Appendix 2}

Students' interview questions

- How did you like the class?

- What did you learn from the class?

- What did you learn from the textbook?

- Do you think the course was useful for your future?

- In what respect?

- Do you think the textbook was useful for your future life?

- What did you think about the textbook?

- What aspect do you think was useful in the textbook?

- What sort of content would be good to include in the textbook?

- Could you relate to the content of the textbook?

- If so, why? If not, why not?

- What sort of Japanese language user do you want to become in the future?

- What do you want to learn from business Japanese classes? Do you think you have achieved it?

- What do you think is important to be able to become a successful business woman in a Japanese language environment?

- Do you think the teacher was taking students' diverse backgrounds into consideration in terms of race and gender?

- Do you think the textbook made you aware of your gender and racial background and identity?

- What does it mean to be an Asian woman and what position does an Asian woman have when doing business in Japanese in the future?

- Do you think the class gave you a different perspective about yourself as a Japanese language learner? 


\section{Reference List}

Allatson, P. 2001, 'Beyond the Hybrid: Notes against Heterophilic Authoritarianism,' genre, no. 22, 191207.

Armour, W. 1998, 'Putting More than Words in their Mouths: Using Model Dialogues to Construct Social Reality in the Japanese Language Classroom,' Japanese Studies Association of Australia, vol. 18 , no. 2, 181-197.

Bhabha, H. K. 1990, 'The Third Space: Interview with Homi Bhabha,' in Identity: Community, Culture, Difference, (ed.) J. Rutherford, Lawrence \& Wishart, London, 207-21.

Bhabha, H. K. 1994, The Location of Culture, Routledge, London; New York. 1996, 'Culture's In-between,' in Questions of Cultural Identity, (eds) S. Hall and P. Du Gay, Sage, London, 53-60.

Dooley, K. 2008, 'Multiliteracies and Pedagogies of New Learning of Students of English as an Additional Language,' in Multiliteracies and Diversity in Education: New Pedagogies for Expanding Landscapes, (ed.) A. Healy, Oxford University Press, Oxford, 102-25.

Easthope, A. 1998, 'Bhabha, Hybridigy and Identity,' Textual Practice, vol. 12, no. 2, 341-48.

Endo, O. 2002a, 'Dansei no Kotoba no Bunmatsu,' in Dansei no Kotoba, Hitsuji Shobō, Tokyo, 33-46. 2002b, 'Shokuba no Dansei no Keigo,' in Dansei no Kotoba Shokuba hen, Hitsuji shobō, Tokyo, 63-74.

Giroux, H. 1990, Curriculum Discourse as Postmodernist Critical Practice, Deakin University, Melbourne.

Giroux, H., Lankashear, C., McLaren, P. and Peters, M. (eds) 1996, Counternarratives: Cultural Studies and Critical Pedagogies in Postmodern Spaces, Routledge, New York and London.

Giroux, H. and McLaren, P. (eds) 1994, Between Borders: Pedagogy and the Politics of Cultural Studies, Routledge, New York and London.

Healy, A. 2008, 'Expanding Student Capacities: Learning by Design Pedagogy,' in Multiliteracies and Diversity in Education: New Pedagogies for Expanding Landscapes, (ed.) A. Healy, Oxford University, Oxford, 2-29.

Ide, S. 1982, 'Gengo to Seisa,' Gengo, vol. 11, no. 10, 40-48.

Ide, S. and Yoshida, M. 1999, 'Sociolinguistics: Honorifics and Gender Differences,' in The Handbook of Japanese Linguistics, (ed.) N. Tsujimura, Blackwell, Oxford, 444-78.

Kawaguchi, Y. 1987, 'Majiriau Danjo no Kotoba,' Gengo Seikatsu, vol. 8, 34-39.

Kawakami, I. 1999, 'Nihonjijō Kyōiku ni Okeru Bunka no Mondai,' 21 Seiki no Nihonjijō, vol. 1, 16-26.

Kawasaki, K. 1997, 'Kyōkasho no Naka no Danjosa,' Gekkan Gengo, vol. 3, 64-67.

Kraidy, M. M. 1999, 'The Global, the Local, and the Hybrid: A Native Ethnography of Glocalization,' Critical Studies in Mass Communication, vol. 16, 456-76.

Kramsch, C. 1993, Context and Culture in Language Teaching, Oxford University Press, Oxford. 1995, 'The Cultural Component of Language Teaching,' Language, Culture and Curriculum, vol. 8, no. 12, 83-92.

Kubota, R. 2003, 'Critical Teaching of Japanese Culture,' Japanese Language and Literature, vol. 37, no. 1, 67-87.

Lo Bianco, J., Liddicoat, A. J. and Crozet, C. (eds) 1999, Striving for the Third Place, Language Australia, Melbourne.

Makino, S. and Tsutsui, M. 1989, A Dictionary of Basic Japanese Grammar, The Japan Times, Tokyo.

Maruyama, K. 2008, 'Nihongo Kyōiku ni oite 'Kyōkasho ga Oshieru' ga Imisuru mono,' Nihongo Kyōiku Ronshū, 24.

Masuoka, T. and Takubo, Y. 1992, Kiso Nihongo Bunpō, Kuroshio, Tokyo.

Matsumoto, Y. and Okamoto, S. 2003, 'The Construction of the Japanese Language and Culture in Teaching Japanese as a Foreign Language,' Japanese Language and Literature, vol. 37, 27-36.

McLaren, P. 1994, 'Multiculturalism and the Postmodern Critique: Toward a Pedagogy of Resistance and Transformation,' in Between Borders: Pedagogy and the Politics of Cultural Studies, (eds) H. Giroux and P. McLaren, Routledge, New York and London, 118-46

Nakada, G. G. 1998, 'Foreign Women Push Business Boundaries,' Japan Quarterly, July-September, 15 22.

Norton, B. 2000, Identity and Language Learning: Gender, Ethnicity and Educational Change, Pearson Education, Harlow.

Norton, B. and Toohey, K. (eds) 2004, Critical Pedagogies and Language Learning, Cambridge University Press, Cambridge.

Ohara, Y., Saft, S. and Crookes, G. 2001, 'Toward a Feminist Critical Pedagogy in a Beginning Japaneseas-a-Foreign-Language Class,' Japanese Language and Literature, vol. 35, 105-33. 
Pennycook, A. 2001, Critical Applied Linguistics: A Critical Introduction, Lawrence Erlbaum Associates, New Jersey.

Perera, S. 1994, 'Unspeakable Bodies: Representing the Aboriginal in Australian Critical Discourse,' Meridian, vol. 13, 15-26.

Pratt, M.-L. 1992, Imperial Eyes: Travel Writing and Transculturation, Routledge, London \& New York. 1994, 'Transculturation and Autoethnography: Peru 1915/1980,' in Colonial Discourse /Postcolonial Theory, (eds) F. Baker, P. Hulme, and M. Iverson, Manchester University Press, New York, 24-46.

Siegal, M. and Okamoto, S. 2003, 'Toward Reconceptualizing the Teaching and Learning of Gendered Speech Styles in Japanese as a Foreign Language,' Japanese Language and Literature, vol. 37, 4966.

Sunderland, J., Cowley, M., Rahim, F. A., Loentzakou, C. and Shattuck, J. 2001, 'From Bias "in the Text" to "Teacher Talk around the Text": An Exploration of Teacher Discourse and Gendered Foreign Language Textbook Texts,' Linguistics and Education, 11, 251-86.

'From Representation Towards Discursive Practices: Gender in the Foreign Language Textbook Revisited,' in Gender Identity and Discourse Analysis, vol. 2, (eds) L. Litosseliti and J. Sunderland, John Benjamins Publisher, Amsterdam/Philadelphia, 223-256.

Takahashi, M. 2002, 'Dansei no Hataraki Kata to Kotoba no Tayōsei,' in Dansei no Kotoba Shokuba hen Hitsuji shobō, Tokyo, 207-235.

Thomson, C. and Iida, S. 2007, 'Josei Hatsuwa 'Mada Meshi Kuttenai' o Meguru Gender to Nihongo Kyōiku no Kōsatsu,' Nihongo Kyōiku, vol. 135, 120-29.

Thomson, C. and Otsuji, E. 2003, 'Evaluation of Business Japanese Textbooks: Issues of Gender,' Japanese Studies, vol. 23, 185-203.

Yoneda, R., Fujii, K., Shigeno, M. and Ikeda, H. 1998, Getting Down to Business: Japanese for Business People (Lower Intermediate level), 3A Corporation, Tokyo.

Yoshioka, Y. 1994, 'Wakai Josei no Gengo Kōdō,' Nihongo Gaku, vol. 13, 33-44. 